\title{
Ophthalmic Emergencies in Benin City, Nigeria
}

\author{
OA Dawodu, AI Osahon, A Atamah, V Okeigbemen
}

Department of Ophthalmology, University of Benin Teaching Hospital, PMB 1111, Benin City, Nigeria

\section{SUMMARY}

Background: The types and causes of ophthalmic emergencies at the University of Benin Teaching Hospital, Benin City were studied prospectively over a 24-month period (January 2002December 2003).

Methods: All emergencies presenting at the University of Benin Teaching Hospital Eye Clinic during this period were recorded. Cases booked for routine clinic visits were excluded. Also excluded were routine referrals to the eye clinic except they required emergency treatment.

Results: Ophthalmic emergencies constituted $1.1 \%$ of all emergencies seen in the hospital. Most of those who presented were children and young adults $\leq 30$ years. Males were more affected with a male: female ratio of 2.9:1. Trauma accounted for $53.4 \%$ of the cases. This was either in the form of corneal/scleral laceration (22\%), traumatic hyphaema $(14.4 \%)$, ruptured globe $(6.1 \%)$, lid laceration $(4.1 \%)$ or burns $(6.8 \%)$. Non-traumatic causes accounted for $34.1 \%$ and were mostly due to infection/inflammatory causes, presenting either as panophthalmitis $(14.4 \%)$, corneal ulcers $(10.6 \%)$, or orbital cellulitis $(9.1 \%)$.

Conclusion: A two-fold strategy for minimizing ophthalmic emergencies and reducing its devastating effects was recommended. Health education would promote the use of protective eyewear for high risk occupations, eradicate late presentation thereby preventing deterioration of minor ocular problems and minimizing severe complications. Adopting the principle of 'injury control' will ensure prevention; provide appropriate emergency medical services for the injured as well as specialized rehabilitation facilities which should attempt to return the individual to their former level of functionality.

Key words: ophthalmic emergencies, Benin City

\section{INTRODUCTION}

Emergencies are a common feature in the practice of ophthalmology all over the world. Injuries to the eye and adnexa constitute a large proportion of ophthalmic emergencies, and are responsible for between $49 \%$ and $65 \%$ in previous studies. ${ }^{1-5}$ Causes of non-traumatic ophthalmic emergencies vary in different parts of the world. Infections/inflammations are common, while in some regions, contact lens related disorders are important. ${ }^{3}$

A prospective study of the pattern of ophthalmic emergencies seen at the University of Benin Teaching Hospital over a 24-month period was conducted with the aim of determining the pattern of common ocular problems that present as emergencies. Preventive strategies especially for those conditions that present frequently can then be planned. It will also assist the management and staff of the unit in planning the best approach for optimal and proper deployment and effective use of the trained staff, as well as building up the capacity of the ophthalmic unit to deal with these emergencies within the limits of available resources.

\section{MATERIALS AND METHODS}

A prospective study was conducted to determine the pattern of ocular emergencies seen at the University of Benin Teaching Hospital. At the end of each working day, a record was kept of all the cases that presented as emergencies to the eye clinic. During the weekend and after the routine working hours, when the eye clinic is usually not open to patients, the ophthalmic resident doctor on call documented the cases seen at the Accident \& Emergency Department of the hospital. Cases that were booked for routine clinic eye visits were excluded; as well as routine referrals from various parts of the hospital were excluded except for those requiring emergency treatment. Age, gender and diagnosis and the point from which the patient was referred was documented. Ocular examination was performed with a pen torch and ophthalmic loupe. Slit lamp examination and applanation tonometry were done as indicated. The posterior segment was examined with direct ophthalmoscope and indirect ophthalmoscope when indicated. Cases requiring emergency surgery were noted and the type of surgery carried out was documented.

Ocular emergency as used in this study meant an ocular

${ }^{*}$ Correspondence: Dr. OA Dawodu, Department of Ophthalmology, University of Benin Teaching Hospital, PMB 1111, Benin City, Nigeria Email: oseluesed@yahoo.com 
condition requiring immediate medical or surgical attention by the ophthalmologist. These were usually conditions that could deteriorate rapidly without such intervention, resulting in either vision loss or severe morbidity or mortality. Examples of medical ocular emergencies were corneal abrasion/ulcer, panophthalmitis and traumatic hyphaema. Examples of surgical emergencies were perforating eye injuries, corneal/conjunctival foreign bodies and chemical burns. Cases such as refractive errors which do not pose a threat to vision, or very rapid deterioration without intervention, were not considered emergencies. Also, minor cases that are usually treated by general practitioners such as conjunctivitis did not require any referral.

\section{RESULTS}

A total of 7,092 medical and 4,861 surgical emergency cases were seen in the 24-month period (from January 2002December 2003), giving a total of 11,953. During this period, 132 ophthalmic emergencies were seen in the eye clinic. This constituted $1.1 \%$ of the total emergencies seen in the hospital.

Of the ophthalmic emergencies, 98 were male and 34 were female, giving a male to female ratio of 2.9:1. Most of the patients (over $70 \%$ ) were aged $\leq 30$ years. Table 1 shows the age and sex distribution of the patients that presented with ophthalmic emergencies.

Table 1. Age and sex distribution of study population

\begin{tabular}{lcccc}
\hline Age & Male & Female & Total & $\%$ \\
\hline $0-10$ & 23 & 7 & 30 & 22.7 \\
$11-20$ & 19 & 9 & 28 & 21.2 \\
$21-30$ & 28 & 6 & 34 & 25.8 \\
$31-40$ & 10 & 4 & 14 & 10.6 \\
$41-50$ & 9 & 2 & 11 & 8.3 \\
$51-60$ & 4 & 2 & 6 & 4.5 \\
$>60$ & 5 & 4 & 9 & 6.8 \\
\hline Total & 98 & 34 & 132 & 100.0 \\
\hline
\end{tabular}

Table 2 shows the types of ocular emergencies seen. The commonest condition was corneal or scleral laceration, which occurred in $22 \%$ of the patients. This was followed by hyphaema and panophthalmitis, which occurred in equal proportions (14.4\% each).

The majority of patients were referred from the Accident and Emergency Unit of the hospital (61.4\%). About $20 \%$ of the patients were referred from the general practice clinic while $13.6 \%$ of the patients reported direct to the eye clinic. Other points of referral are as shown on table 3 .
Table 2. Types of ocular emergencies

\begin{tabular}{lcc}
\hline Type of Emergency & Number & $\%$ \\
\hline Corneal/scleral laceration & 29 & 22.0 \\
Hyphaema & 19 & 14.4 \\
Panophthalmitis & 19 & 14.4 \\
Corneal ulcer & 14 & 10.6 \\
Orbital cellulitis & 12 & 9.1 \\
Chemical/thermal burns & 9 & 6.8 \\
Ruptured globe & 8 & 6.1 \\
Lid laceration & 6 & 4.6 \\
Corneal FB/keratitis & 5 & 3.8 \\
Intraocular/intraorbital FB & 4 & 3.0 \\
Iritis/blunt trauma & 4 & 3.0 \\
Others & 3 & 2.3 \\
\hline Total & 132 & 100.0 \\
\hline
\end{tabular}

Table 3. Points of referral of emergency cases to the eye clinic

\begin{tabular}{lcc}
\hline Point of Referral & Number & $\%$ \\
\hline Accident and & 81 & 61.4 \\
Emergency Unit & & \\
General Practice Clinic & 27 & 20.5 \\
Presented directly to & 18 & 13.6 \\
eye clinic & & \\
Staff Clinic & 4 & 3.0 \\
Optometrist & 2 & 1.5 \\
\hline Total & 132 & 100.0 \\
\hline
\end{tabular}

Table 4. Types of emergency surgeries performed

\begin{tabular}{lcc}
\hline Type of Surgery & Number & $\%$ \\
\hline Corneal/scleral repair & 31 & 50.8 \\
Evisceration/enucleation & 11 & 18.0 \\
Repair of lid laceration & 7 & 11.5 \\
Anterior chamber washout* & 6 & 9.8 \\
$\begin{array}{l}\text { Examination under anaesthesia } \\
\text { (EUA) }\end{array}$ & 2 & 3.3 \\
$\begin{array}{l}\text { Incision and drainage of orbital } \\
\text { abscess }\end{array}$ & 2 & 3.3 \\
$\begin{array}{l}\text { Conjunctival flap for imminent } \\
\text { rupture of corneal ulcer }\end{array}$ & 2 & 3.3 \\
\hline $\begin{array}{l}\text { Total } \\
\text { *Some patients that had corneal/scleral }\end{array}$ & repair also had anterior \\
chamber washout as well. &
\end{tabular}




\section{DISCUSSION}

The peak age for presenting with an ocular emergency in this study was $21-30$ years. Over $25 \%$ of all patients belonged to this group. This may be because this age group is active and therefore predisposed to circumstances that cause ocular injury. This is similar to the findings of Edwards ${ }^{2}$ and Tsai ${ }^{3}$ in the United Kingdom and Taiwan respectively. The male to female ratio was also similar, with a preponderance of male patients. This is probable due to the fact that males are more exposed to the more risky aspects of farm work such as bush clearing, and are also more likely to engage in dangerous activities than females. ${ }^{6}$ Children and adolescents are frequently injured during unsupervised play in school and at home, therefore presenting as ophthalmic emergencies. ${ }^{7}$ As seen in table 1, children aged 0-10 years and adolescents aged 11-20 years were also greatly affected, together these groups contributed $43.9 \%$ of the total ophthalmic emergencies seen.

There is a difference in the aetiology of injuries in studies from developed and developing countries. Studies from developed countries report most cases of injuries that present as emergencies as being minor such as abrasions and corneal/conjunctival foreign bodies, ${ }^{1,-3}$ whereas studies from developing countries report more severe injuries such as stick injury and ruptured globe. ${ }^{8,9}$ There is also a variation in the type of infective/ inflammatory causes of ophthalmic emergencies. More developed countries report cases such as acute conjunctivitis, blepharitis and contact lens related disorders, ${ }^{2,3}$ while the infective/ inflammatory causes in developing countries were from corneal ulceration and uveitis. ${ }^{4,8}$ This may be attributed to the fact that primary eye care is functional in many developed nations, ${ }^{10}$ while developing nations have a dearth of eye care professionals with poor coverage of the population with primary eye care services, especially in the rural communities. This has made self-medication and late presentation a common practice. ${ }^{4,8,11}$ The result is that even relatively minor injuries that could have resolved with appropriate therapy are left to deteriorate to more major eye ailments. The severe injuries seen as emergencies in developing countries are frequently occupational (from farming, welding, etc), mostly due to lack of use of protective eye wear. Since the agricultural sector is yet to be mechanized, a lot of our agricultural workers still work with hoes and cutlasses for manual bush clearing often resulting in eye injuries that are sometimes severe. Comparatively, the trauma cases that present as emergencies in developed countries are more frequently from sport injuries and play. The number of people wearing contact lenses in developing countries at the moment is negligible hence contact lens problems are not common.

Most of the patients seen as emergency cases were referred from the accident and emergency unit of the hospital. This is likely due to the fact that it is open to patients 24 hours a day and seven days a week whereas the eye clinic is only open to patients during working hours (8am-4pm) which is eight hours a day. The General Practice Clinic (GPC) also referred a fairly large number of emergency cases because that is the usual 'first contact' for all new patients presenting to the University of Benin Teaching Hospital. Only those cases considered severe or requiring specialist attention were referred. As a result of this practice, minor eye ailments such as conjunctivitis and lid abrasions were treated at this level without referral. Those who presented to the eye clinic directly are those who were referred from other hospitals to the UBTH ophthalmology department or have been seen in the eye clinic on a previous occasion and so had the eye clinic registration card from previous visits.

The types of surgeries performed mirrored the types of cases that presented as emergencies. The commonest emergency cases seen were corneal/scleral laceration and surgical repair of corneal/scleral laceration was also the most common surgery performed. This was followed by enucleation/evisceration which was usually done for cases of panophthalmitis and orbital cellulitis which failed to respond to maximum medical treatment. The left eyes were more commonly involved in trauma than the right, but most of the burn patients had bilateral involvement.

The term, 'accident prevention', has been replaced by 'injury control' ${ }^{12}$ The word accident by definition implies an event occurring by chance, without pattern or predictability. ${ }^{13}$ Advances have identified the risk factors for injuries. $^{12}$ Most injuries occur under fairly predictable circumstances to high-risk children and families and successful programmes for prevention and control have been developed. ${ }^{12}$ Reduction of morbidity and mortality from injuries can be accomplished not only through primary prevention (averting the event or injury) but also through secondary and tertiary prevention. Secondary prevention involves appropriate emergency medical services for the injured while tertiary prevention provides specialized rehabilitation, which attempts to return the individual to their prior level of functionality. This broadened scope of prevention is what is described as injury control. ${ }^{12}$

Trauma was the commonest cause of emergency care in the eye unit. About a third (33.4\%) was from lacerations of the cornea/sclera, eyelids or burns. Blunt trauma resulting in hyphaema or iritis was also fairly common, together (iritis, blunt trauma and hyphaema) accounting for $17.4 \%$. Infective/ inflammatory causes were responsible for $34.1 \%$ of cases. These presented in the form of panophthalmitis, corneal ulceration or orbital cellulitis. Many of the cases of corneal ulceration and panophthalmitis seen originated from minor ocular trauma such as corneal abrasions, which, if given immediate and appropriate treatment, would not 
deteriorate to perforation, panophthalmitis or orbital cellulitis.

The main method of minimizing ophthalmic emergencies and reducing its devastating effects should be twofold. Health education would promote the use of protective eye wear for high risk occupations, eradicate late presentation thereby preventing deterioration of minor ocular problems and minimizing severe complications. This will reduce the loss of man hours due to morbidity, visual loss, blindness and mortality from injuries or complications. The second approach is to adopt the principle of 'injury control' which will not only ensure prevention, but will also put in place appropriate emergency medical services for the injured as well as specialized rehabilitation facilities which should attempt to return the individual to their prior level of functionality.

\section{REFERENCES}

1. Nash EA, Margo CE. Pattern of emergency department visits for disorders of the eye and ocular adnexa. Arch Ophthalmol 1998; 116: 1222-6.

2. Edwards RS. Ophthalmic emergencies in a district general hospital casualty department. Br J Ophthalmol. 1987; 71: 938942.

3. Tsai CC, Kau HC, Kao SC, Liu JH. A review of ocular emergencies in a Taiwanese medical centre. Zhonghua Yi Xue Za Zhi (Taipei) 1998; 61(7): 414-20.

4. Kaimbo WK, Spileers W, Missotten L. Ocular emergencies in
Kinshasa. (Democratic Republic of Congo). Bull Soc Belge Ophthalmol 2002; 284: 49-53.

5. Verma L, Arora R, Tewari HK, Khosla PK. Eye casualty department. Journal of the Royal Society of Medicine 1994; 87(4): 217-218.

6. Dawodu OA, Ukponmwan CU. Corneal ulcers. Experience at Otibhor Okhae Teaching Hospital, Irrua. Nigerian Journal of Surgical Sciences 2003; 12(2): 65-69.

7. Omoti AE. Ocular trauma in Benin City, Nigeria. African J Trauma 2004; 2 (2-4): 67-71

8. Abraham DI, Vitale SI, West SI, Isseme I. Epidemiology of eye injuries in rural Tanzania. Ophthalmic Epidemiol 1999; 6(2): 8594.

9. Meda N, Quedraogo A, Daboue A, Quedraogo M, Ramde B, Some D, Sanou A. Etiologies of eyelid trauma in Burkina Faso. Service d'Ophthalmologie, center Hospitalier National Yalgado Quedraogo, B.P.7, 022 Quagadougou 03 Burkina Faso.

10. Riad SF, Dart JKG, Cooling RJ. Primary care and ophthalmology in the United Kingdom. British Journal of Ophthalmology 2003; 87: 493-499.

11. Dawodu OA. The hazards of ocular self-medication. Sahel Medical Journal 1999; 2(2): 111-113.

12. Behrman RE, Kliegman RM, Jenson HB. Nelson Textbook of Pediatrics. Saunders. 17 ${ }^{\text {th }}$ edition. 2004: 256.

13. AS Hornby. Oxford Advanced Level Learners Dictionary. Fifth Edition. Oxford University press 1998; 7. 